\title{
Role of Calcium and Phosphoinositides in the Actions of Certain Hormones and Neurotransmitters
}

\author{
John H. Exton \\ Laboratories for the Studies of Metabolic Disorders, Howard Hughes Medical Institute, and the Department of Physiology, \\ Vanderbilt University School of Medicine, Nashville, Tennessee 37232
}

\section{Introduction}

Many hormones and neurotransmitters exert some of their effects by raising the $\mathrm{Ca}^{2+}$ concentration in the cytosol of their target cells. Examples of such agonists are epinephrine, norepinephrine, acetylcholine, vasopressin, angiotensin II, cholecystokinin, histamine, serotonin, substance $P$, some of the hypothalamic releasing hormones, platelet activating factors, and chemotactic peptides. These agonists exert their effects on cell $\mathrm{Ca}^{2+}$ by interacting with surface receptors that are distinct from those that mediate changes in cyclic AMP (cAMP) e.g., $\alpha_{1}$-adrenergic, M1 muscarinic cholinergic, V1 vasopressin, and $\mathrm{H} 1$ histamine receptors. Typical $\mathrm{Ca}^{2+}$-mediated responses are the contraction of smooth muscle in blood vessels and other tissues, the secretion of salivary, lacrimal, sweat, and pancreatic glands, the release of certain pituitary hormones, aldosterone and insulin, and secretory or other responses in platelets, neutrophils, mast cells, and lymphocytes. In addition, many $\mathrm{Ca}^{2+}$-mediated agonists act as neurotransmitters.

\section{Changes in cell calcium induced by calcium-} mediated agonists

Fig. 1 shows the mechanisms involved in the regulation of $\mathrm{Ca}^{2+}$ in mammalian cells. $\mathrm{Ca}^{2+}$ enters cells through selective plasma membrane channels that are either membrane potentialdependent or -independent (1). In addition, $\mathrm{Ca}^{2+}$ may enter through the $\mathrm{Na}^{+}$channel or by a $\mathrm{Na}^{+} / \mathrm{Ca}^{2+}$ exchanger (1).

To prevent the pathological accumulation of $\mathrm{Ca}^{2+}$, cells possess a plasma membrane $\mathrm{Ca}^{2+}$ ATPase pump that maintains cytosolic $\mathrm{Ca}^{2+}$ at a resting level of $0.1-0.2 \mu \mathrm{M}$ (1). The $\mathrm{Na}^{+} /$ $\mathrm{Ca}^{2+}$ exchanger also acts mainly to extrude $\mathrm{Ca}^{2+}(1)$. The $\mathrm{Ca}^{2+}$ pump acts as a low capacity system with high affinity for $\mathrm{Ca}^{2+}$, whereas the reverse is true for the exchanger.

In addition to plasma membrane systems, intracellular mechanisms control cytosolic $\mathrm{Ca}^{2+}$ (Fig. 1). These mainly involve the endoplasmic (sarcoplasmic) reticulum and mitochondria, which take up or release $\mathrm{Ca}^{2+}(2)$. Certain membranes and other cellular constituents also bind and buffer cytosolic $\mathrm{Ca}^{2+}$. $\mathrm{Ca}^{2+}$ uptake by endoplasmic reticulum occurs by an ATPase, whereas that by mitochondria involves a specific carrier and is driven by the proton mu. . force (2). Less is known about the $\mathrm{Ca}^{2+}$ efflux pathways of either organelle. Recent evidence suggests that the endoplasmic reticulum is

Dr. Exton is an Investigator of the Howard Hughes Medical Institute. Received for publication 4 March 1985.

J. Clin. Invest.

(c) The American Society for Clinical Investigation, Inc. 0021-9738/85/06/1753/05 $\$ 1.00$

Volume 75 , June 1985, 1753-1757 the major organelle regulating cytosolic $\mathrm{Ca}^{2+}$ within the physiological range $(0.1 \mu \mathrm{M}-1 \mu \mathrm{M})(3)$.

Calcium-mediated agonists increase cytosolic $\mathrm{Ca}^{2+}$ by several mechanisms. There is usually an initial mobilization of intracellular $\mathrm{Ca}^{2+}$, occurring within seconds, followed by altered $\mathrm{Ca}^{2+}$ movement across the plasma membrane $(2,4)$. Endoplasmic reticulum is the major source of mobilized $\mathrm{Ca}^{2+}(5)$, but it possibly also comes from mitochondria or the plasma membrane $(2,4)$. The mechanism of release of internal $\mathrm{Ca}^{2+}$ (Fig. 2) is discussed in detail below.

The internal stores of $\mathrm{Ca}^{2+}$ in most cells are limited. Therefore, a hormone effect based solely on intracellular $\mathrm{Ca}^{2+}$ release would be of short duration, since $\mathrm{Ca}^{2+}$ released into the cytosol is rapidly extruded by the plasma membrane pump (4). $\mathrm{Ca}^{2+}$-mediated agonists, therefore, also affect the flux of $\mathrm{Ca}^{2+}$ across the plasma membrane and prolong the increase in cytosolic $\mathrm{Ca}^{2+}$ and resultant physiological responses $(1,4)$. Many reports indicate that $\mathrm{Ca}^{2+}$-mediated agonists increase the $\mathrm{Ca}^{2+}$ permeability of the plasma membrane (1). This is shown by ${ }^{45} \mathrm{Ca}^{2+}$ flux studies and the inhibitory effects of $\mathrm{Ca}^{2+}$ channel blockers on some responses. Alternatively, certain agonists inhibit the plasma membrane $\mathrm{Ca}^{2+} \mathrm{ATPase}$ /pump (4). The mechanisms by which the agonists open $\mathrm{Ca}^{2+}$ channels or inhibit the $\mathrm{Ca}^{2+}$ pump are presently unknown.

\section{Calmodulin-dependent and-independent processes} involved in the actions of calcium-mediated agonists

As illustrated in Fig. 2, many responses to $\mathrm{Ca}^{2+}$-mediated agonists involve binding of $\mathrm{Ca}^{2+}$ to calmodulin and subsequent interaction of the $\mathrm{Ca}^{2+}$-calmodulin complex with specific or multifunctional calmodulin-dependent protein kinases or other enzymes and proteins (6). In addition, the diacylglycerol released during agonist-induced breakdown of plasma membrane phosphoinositides (Fig. 2) produces responses through activation of protein kinase $\mathrm{C}, \mathrm{a} \mathrm{Ca}^{2+}$-phospholipid-dependent protein kinase (7).

Smooth muscle contraction is a major response to norepinephrine, acetylcholine, and many other $\mathrm{Ca}^{2+}$-mediated agonists. The mechanism involves a rise in cytosolic $\mathrm{Ca}^{2+}$, leading to an increase in $\mathrm{Ca}^{2+}$ bound to calmodulin, which increases the activity of myosin light chain kinase and leads to phosphorylation of the 22,000-mol-wt light chains of myosin (6). Since smooth muscle myosin must be phosphorylated to interact with actin, the mechanism increases myosin ATPase activity and cross-bridge cycling, i.e., contraction. Protein kinase $C$ can also phosphorylate myosin light chains (8) and may be involved in contraction in some smooth muscles (9).

A rise in cytosolic free calcium concentration may exert some effects more directly. For example, calcium binds to 


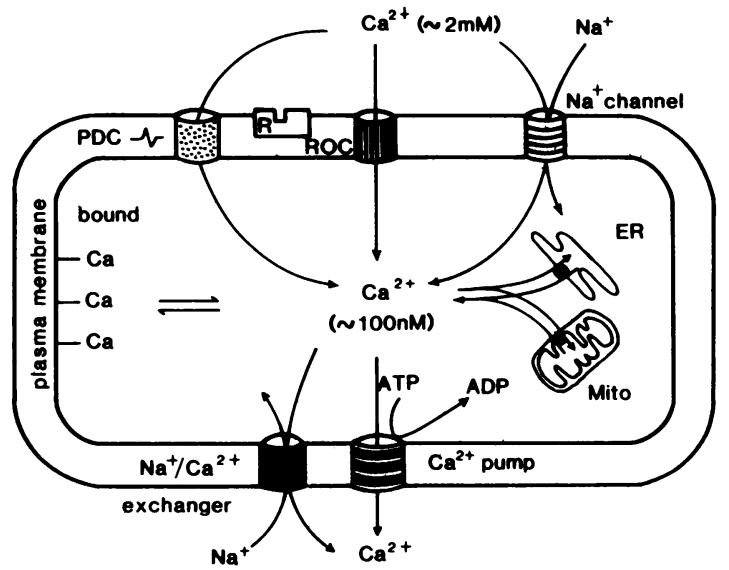

Figure 1. General mechanisms of regulation of cytosolic $\mathrm{Ca}^{2+}$ in cells. ER, endoplasmic reticulum; Mito, mitochondria; PDC, potentialdependent channels; ROC, receptor-operated channels.

troponin, allowing myosin to interact with actin, thus leading to contraction of skeletal and cardiac striated muscles (10). Other direct-acting intracellular receptors of calcium are among a class of proteins that includes gelsolin, villin, and fragmin. These proteins, in the presence of submicromolar calcium nucleate actin filament assembly, sever actin filaments along their lengths and block actin monomer exchange at their fastgrowing ends (11). These effects may be important for rapid cell shape changes and for secretion by exocytosis.

Secretory responses in salivary, lacrimal and sweat glands, and in exocrine pancreas and gastric parietal cells are observed with certain $\mathrm{Ca}^{2+}$-mediated agonists. In salivary and lacrimal glands, the rise in cytosolic $\mathrm{Ca}^{2+}$ increases the $\mathrm{K}^{+}$permeability of the plasma membrane (12), and there is evidence that the resulting outflow of $\mathrm{K}^{+}$leads to the secretion of $\mathrm{H}_{2} \mathrm{O}, \mathrm{Na}^{+}$, and $\mathrm{Cl}^{-}$. Protein kinase $\mathrm{C}$ appears not to be involved in the increase in $\mathrm{K}^{+}$permeability, although it may play a role in amylase secretion (13).

The stimulation of aldosterone secretion by angiotensin II $(14,15)$, of prolactin and thyroid-stimulating hormone by thyrotropin-releasing hormone (16-19), and of insulin by

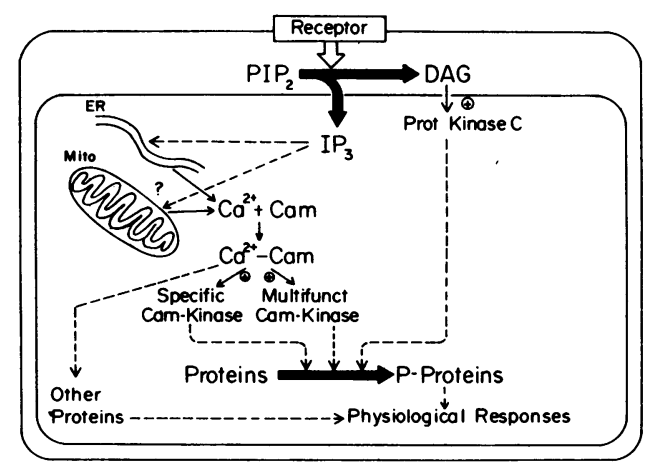

Figure 2. General mechanisms by which $\mathrm{Ca}^{2+}$-mediated agonists produce their physiological responses. The scheme does not show the alterations in $\mathrm{Ca}^{2+}$ fluxes across the plasma membrane since their mechanisms are unknown. Examples of specific Cam (calmodulindependent) protein kinases are myosin light chain kinase and phosphorylase kinase. Other definitions are given in the text or in the legend to Fig. 1. glucose (20-23) appears to involve both $\mathrm{Ca}^{2+}$ and $\mathrm{Ca}^{2+}$ calmodulin-dependent protein kinase(s) and diacylglycerol and protein kinase C. For example, thyrotropin-releasing hormone increases the phosphorylation of six cytosolic proteins in pituitary cells (19). Two of these phosphorylations are attributable to $\mathrm{Ca}^{2+}$, whereas the others apparently involve protein kinase $C(19)$. It has been speculated that phosphorylation of several islet proteins, including those associated with microtubules, microfilaments, and secretory granules, by $\mathrm{Ca}^{2+}$. calmodulin-dependent protein kinase and/or protein kinase $\mathrm{C}$ underlies glucose-induced insulin secretion (21-23).

Platelet-activating agents cause platelet aggregation and secretion through mechanisms involving both $\mathrm{Ca}^{2+}$-calmodulindependent protein kinase(s) and protein kinase $C(5,7,24)$. The initial shape change appears to involve phosphorylation of myosin light chains (25).

$\mathrm{Ca}^{2+}$-mediated agonists cause a rapid breakdown of glycogen in liver due to activation of glycogen phosphorylase and inactivation of glycogen synthase (4). Phosphorylase activation is due to $\mathrm{Ca}^{2+}$ stimulation of phosphorylase kinase, which contains calmodulin as a subunit (4). Inactivation of glycogen synthase could involve phosphorylase kinase, protein kinase $\mathrm{C}$, or a multifunctional $\mathrm{Ca}^{2+}$-calmodulin-dependent protein kinase $(4,26)$. The latter two kinases are probably responsible for the other effects of $\mathrm{Ca}^{2+}$-mediated agonists on liver.

$\mathrm{Ca}^{2+}$-mediated neurotransmitters increase the phosphorylation of specific proteins that are either located throughout the nervous system or limited to one or a few neuron types $(27,28)$. Many of these proteins are substrates of $\mathrm{Ca}^{2+}$ calmodulin-dependent protein kinases and/or protein kinase C (27-29) and are phosphorylated during electrical or drug stimulation $(27,28)$. For example, the calmodulin-dependent kinase phosphorylates synapsin 1, which is associated with synaptic vesicles in nerve terminals and controls neurotransmitter release, tyrosine and tryptophan hydroxylases, which control dopamine, norepinephrine or serotonin synthesis, and microtubule and associated proteins (27-29). Protein kinase C also phosphorylates many neuronal proteins, including an 87,000 -mol-wt protein present in all neurons, and the nicotinic acetylcholine receptor (27-29)

\section{Role of phosphoinositide breakdown in the mechanisms of} action of calcium-mediated agonists

There is much current excitement concerning the hypothesis that $\mathrm{Ca}^{2+}$-mediated agonists act by stimulating the breakdown of phosphoinositides in the plasma membrane $(5,30)$. The hypothesis arose from the pioneering work of Michell and others (31) and is depicted in Fig. 2. It postulates that interaction of $\mathrm{a} \mathrm{Ca}^{2+}$-mediated agonist with its receptor stimulates the breakdown of phosphatidylinositol 4,5-bisphosphate $\left(\mathrm{PIP}_{2}\right)^{1}$ by a phosphodiesterase (phospholipase C) to yield two intracellular "messengers," myoinositol 1,4,5-trisphosphate (IP $\left.{ }_{3}\right)$ and 1,2-diacylglycerol (DAG) $(5,30) . \mathrm{IP}_{3}$ then enters the cytosol and releases $\mathrm{Ca}^{2+}$ from endoplasmic reticulum $(5,30)$, and perhaps other stores (Thiyagarajah, P., R. Charest, J. H. Exton, and P. F. Blackmore, manuscript submitted for publication), leading to some of the cellular responses described in

1. Abbreviations used in this paper: DAG, 1,2-diacylglycerol; EGF, epidermal growth factor; $\mathrm{IP}_{3}$, myoinositol 1,4,5-trisphosphate; PI, phosphatidylinositol; PIP, phosphatidylinositol 4-phosphate; PIP $_{2}$, phosphatidylinositol 4,5-bisphosphate; PMA, phorbol myristate acetate. 
the preceding section. DAG simultaneously increases in the plasma membrane, where it activates protein kinase $C(5,7$, 30). This enzyme phosphorylates substrates in or near the membrane or may be released into the cytosol.

PIP $_{2}$ is a very minor phospholipid formed in the plasma membrane by the sequential phosphorylation of phosphatidylinositol (PI) and phosphatidylinositol 4-phosphate (PIP) by specific kinases (Fig. 3) $(5,30)$. It has also been reported that certain tyrosine kinases encoded by viral oncogenes (pp60 $0^{\text {sc }}$ and $\left.p 68^{r o s}\right)(5,30)$, the insulin receptor tyrosine kinase $(32)$, and cAMP-dependent protein kinase (33) phosphorylate PI or PIP in vitro. However, the purity of the kinases used in these experiments may be questioned, and at present, the evidence that they control PI phosphorylation in intact cells is equivocal (e.g., 34). The effects of other oncogene products and growth factors on phosphoinositide metabolism are described below.

PIP $_{2}$ and PIP can be reconverted to PI by the action of phosphomonoesterases (Fig. 3). In platelets and some other cells, another major pathway of phosphoinositide metabolism is hydrolysis by phospholipase $A_{2}$ to yield arachidonic acid, which is then converted to a variety of bioactive eicosanoids $(7,30)$.

As is true for all intracellular messengers, $\mathrm{IP}_{3}$ and DAG turn over rapidly. As shown in Fig. $3, \mathrm{IP}_{3}$ is sequentially degraded by phosphatases (5) to myoinositol 1,4-bisphosphate, myoinositol 1-phosphate, and myoinositol. None of these is effective in mobilizing intracellular $\mathrm{Ca}^{2+}(5)$. DAG is converted to phosphatidic acid by diacylglycerol kinase in the plasma membrane (Fig. 3) (7, 30). It can also be hydrolysed by diacylglycerol and monoacylglycerol lipases $(7,30)$, but these enzymes are mainly located in sites other than the plasma membrane. Phosphatidate formed from DAG is transferred to the endoplasmic reticulum and used for the synthesis of phospholipids and triacylglycerol (Fig. 3) $(5,30)$.

In all of many tissues examined, the first event detected after receptor occupancy by $\mathrm{Ca}^{2+}$-mediated agonists is the breakdown of $\mathrm{PIP}_{2}$ and formation of $\mathrm{IP}_{3}$. This occurs sufficiently rapidly to account for the increase in cytosolic $\mathrm{Ca}^{2+}(5,30$, 35). Concentrations of $\mathrm{IP}_{3}(20-300 \mathrm{nM})$, which resemble those

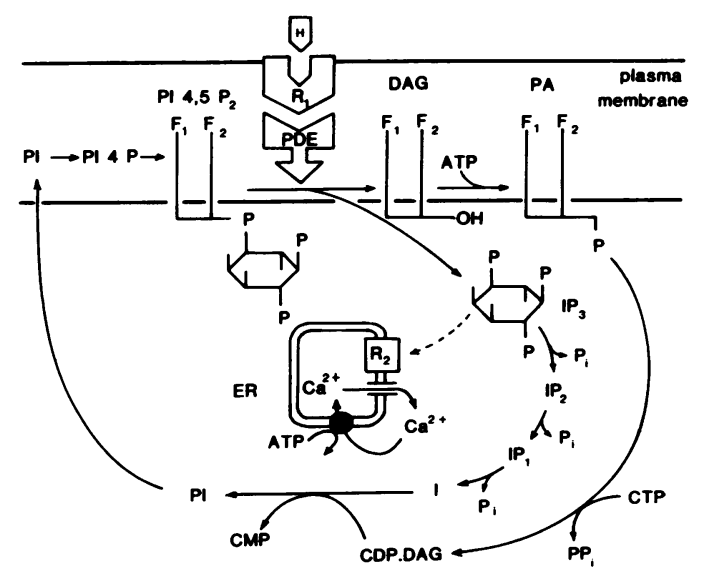

Figure 3. Changes in phosphoinositide metabolism induced by $\mathrm{Ca}^{2+}$ mediated agonists. $F_{1}$, fatty acid $1 ; F_{2}$, fatty acid $2 ; \mathrm{H}$, hormone or agonist; $\mathrm{IP}_{1}$, myoinositol 1-phosphate; $\mathrm{P}$, phosphate; PA, phosphatidic acid; PDE, phosphodiesterase or phospholipase C; PI4P, PIP; PI4,5P $\mathbf{P}_{2}, \mathrm{PIP}_{2} ; \mathbf{R}_{1}$, surface receptor; $\mathbf{R}_{2}$, putative ER (endoplasmic reticulum) receptor for $\mathrm{IP}_{3}$. calculated to occur in the cytosol, also instantly release intracellular $\mathrm{Ca}^{2+}$ in permeabilized cells of several types $(5,30)$ (Thiyagarajah, P., R. Charest, J. H. Exton, and P. F. Blackmore, manuscript submitted for publication) and mobilize $\mathrm{Ca}^{2+}$ from isolated microsomes (5) and mitochondria (Thiyagarajah, P., R. Charest, J. H. Exton, and P. F. Blackmore, manuscript submitted for publication). These observations strongly support the postulated role of $\mathrm{IP}_{3}$ as the messenger for intracellular $\mathrm{Ca}^{2+}$ mobilization.

Due to the presence of spare receptors for most $\mathrm{Ca}^{2+}$. mediated agonists, occupancy of only a fraction of total receptors with the generation of submaximal concentrations of $\mathrm{IP}_{3}$ is sufficient to elicit maximal physiological responses in most situations (Lynch, C. J., P. F. Blackmore, R. Charest, and J. H. Exton, manuscript submitted for publication). This signal amplification resembles that observed for many cAMPmediated agonists and gives rise to a large separation in the dose-response curves for $\mathrm{IP}_{3}$ formation and responses in certain cells (35).

Little is known concerning the coupling of receptors to $\mathrm{PIP}_{2}$ breakdown, but there is indirect evidence that a guanine nucleotide binding regulatory protein is involved, as is the case for the receptors coupled to adenylate cyclase. For example, GTP analogues modify $\mathrm{Ca}^{2+}$-mediated actions in platelets and mast cells $(36,37)$, and a pertussis toxin that ADP-ribosylates the inhibitory guanine nucleotide binding protein $\mathrm{N}_{\mathrm{i}}$ of adenylate cyclase inhibits $\mathrm{Ca}^{2+}$-mediated responses in neutrophils and mast cells $(38-40)^{2}$

Platelet-derived growth factor stimulates $\mathrm{IP}_{3}$ formation and mobilizes $\mathrm{Ca}^{2+}$ in Swiss $3 \mathrm{~T} 3$ cells $(5,30)$, and epidermal growth factor (EGF) increases PI turnover and cytosolic $\mathrm{Ca}^{2+}$ in other cells $(5,30)$. Certain viral oncogenes code for plateletderived growth factor (sis), a truncated EGF receptor (erbB), and guanine nucleotide binding proteins (ras) (5). EGF stimulates the activity of the ras proteins through tyrosine phosphorylation (42). These findings indicate that certain growth factors and oncogenes may also act through the phosphoinositide pathway.

\section{Role of diacylglycerol and protein kinase $C$}

DAG responses to $\mathrm{Ca}^{2+}$-mediated agonists have been measured in several tissues, including platelets, pituitary, adrenal, and liver cells. Concentrations of agonists effective on $\mathrm{Ca}^{2+}$ mobilization rapidly increase DAG in these cells $(7,15,43-46)$ (Bocckino, S. B., P. F. Blackmore, and J. H. Exton, manuscript submitted for publication). Analysis of the fatty acid composition of the DAG or phosphatidic acid generated in platelets and hepatocytes shows enrichment in arachidonic and stearic acids, indicating they are derived in part from phosphoinositides $(43,47) .^{3}$

2. Involvement of a guanine nucleotide binding regulatory protein is further suggested by the findings that micromolar concentrations of GTP stimulate the breakdown of $\mathrm{PIP}_{2}$ to $\mathrm{IP}_{3}$ in liver plasma membranes (Uhing, R. J., H. Jiang, and J. H. Exton, manuscript submitted for publication) and inhibit the binding of $\mathrm{Ca}^{2+}$-mediated agonists to these membranes (41).

3. Fractionation of DAG by high pressure liquid chromatography shows two major fractions: one enriched in arachidonic and stearic acids, the other in palmitic and linolenic acids. This indicates another source of DAG besides phosphoinositides (Bocckino, S. B., P. F. Blackmore, and J. H. Exton, manuscript submitted for publication). 
Diacylglycerol containing at least one unsaturated fatty acid activates protein kinase $\mathrm{C}$ by decreasing its requirement for $\mathrm{Ca}^{2+}(7,48)$. This enzyme has an absolute requirement for $\mathrm{Ca}^{2+}$ and a phospholipid such as phosphatidylserine $(7,48$, 49 ), and addition of unsaturated diacylglycerol permits the enzyme to function at cytosolic $\mathrm{Ca}^{2+}$ concentrations $(7,48$, 49). Tumor-promoting phorbol esters such as $4 \beta$-phorbol, $12 \beta$ myristate, $13 \alpha$-acetate (PMA) are structurally similar to diacylglycerol and also activate protein kinase C (49). Because of this, phorbol esters and synthetic diacylglycerols are used to probe the role of protein kinase $\mathrm{C}$ in certain cellular responses. Although it is generally assumed that these agents act primarily or solely through this enzyme, this may not always be the case.

Because of its requirement for lipids, protein kinase $\mathrm{C}$ may not function in the cytosol. Thus soluble substrates may have to migrate to the membrane-bound enzyme. Many proteins are substrates of protein kinase $\mathrm{C}$ in vitro, but it is less clear whether they are phosphorylated by the enzyme in vivo. The identities of most proteins phosphorylated in intact tissues in response to PMA are unknown, except for myosin light chains (50), glycogen synthase (51), and insulin and EGF receptors $(52,53)$. PMA inhibits binding to the insulin, EGF, and $\alpha_{1}$ adrenergic receptors (54-56), suggesting that protein kinase $C$ may regulate these and other receptors.

In many cell types, the $\mathrm{Ca}^{2+}$ pathway of agonist action interacts synergistically with the DAG pathway $(7,30)$. This synergism is seen in the aggregatory and secretory responses of platelets $(7,24,30)$, exocytosis in neutrophils $(5,7,57)$, histamine release from mast cells (7), aldosterone and insulin secretion $(5,15,58)$, contraction in certain smooth muscles $(5,9,59)$, and mitosis in lymphocytes (7). The synergism may be due to the combined effects of $\mathrm{Ca}^{2+}$ and DAG on protein kinase $\mathrm{C}$ or to more distal events. For example, the response may depend on the phosphorylation of one or more proteins by both calmodulin- and phospholipid-dependent protein kinases or on the interaction of several proteins phosphorylated by either kinase.

In summary, there has been much recent progress in understanding the molecular mechanisms by which $\mathrm{Ca}^{2+}$. mediated agonists exert their widespread physiological effects. Of particular interest is the fact that two intracellular messengers are involved, namely, $\mathrm{Ca}^{2+}$ and diacylglycerol. These may act separately to produce physiological responses, but often they interact synergistically. Despite the rapid advance in knowledge in this area, many points remain to be clarified. These include the coupling between the receptors and $\mathrm{PIP}_{2}$ breakdown, the mechanism by which $\mathrm{IP}_{3}$ releases intracellular $\mathrm{Ca}^{2+}$, the changes in plasma membrane $\mathrm{Ca}^{2+}$ fluxes and how they are caused, and the enzymes and other proteins involved in all the responses to the agonists.

\section{Acknowledgments}

I thank Peter Blackmore for Figs. 1 and 3 and Carolyn Sielbeck for typing the manuscript.

Some of the research reported was supported by grants AM18660 and AM33291 from the National Institutes of Health.

\section{References}

1. Barritt, G. J. 1982. In The Role of Calcium in Biological Systems, Vol. 2. L. J. Anghileri and A. M. Tuffet-Anghileri, editors. CRC Press, Inc., Boca Raton, FL. pp. 17-30.

2. Williamson, J. R., R. H. Cooper, and J. B. Hoek. 1981. Biochim. Biophys. Acta. 639:243-295.

3. Burgess, G. M., J. S. McKinney, A. Fabiato, B. A. Leslie, and J. W. Putney, Jr. 1983. J. Biol. Chem. 258:15336-15345.

4. Blackmore, P. F., and J. H. Exton. 1985. In Biochemical Actions of Hormones. G. Litwak, editor. Academic Press, New York. In press.

5. Berridge, M. J., and R. F. Irvine. 1984. Nature (Lond.). 312: 315-321.

6. Manalan, A. S., and C. Klee. 1984. Adv. Cyclic Nucleotide Res. 18:227-278.

7. Nishizuka, Y. 1984. Nature (Lond.). 308:693-698.

8. Naka, M., M. Nishikawa, R. S. Adelstein, and H. Hidaka. 1983. Nature (Lond.). 306:490-492.

9. Rasmussen, H., J. Forder, I. Kojima, and A. Scriabine. 1984. Biochem. Biophys. Res. Commun. 122:776-784.

10. Ebashi, S. 1972. Nature (Lond.). 240:217-218

11. Stossel, T. P. 1984. J. Cell Biol. 99:155-215.

12. Putney, J. W., Jr. 1979. Pharmacol. Rev. 30:209-245.

13. Putney, J. W., Jr., J. S. McKinney, D. L. Aub, and B. A. Leslie. 1984. Mol. Pharmacol. 26:261-266.

14. Capponi, A. M., P. D. Lew, L. Jornot, and M. Valotton. 1984. J. Biol. Chem. 259:8863-8869.

15. Kojima, I., K. Kojima, D. Kreutter, and H. Rasmussen. 1984. J. Biol. Chem. 259:14448-14457.

16. Albert, P. R., and A. H. Tashjian, Jr. 1984. J. Biol. Chem. 259:5827-5832.

17. Geras, E. J., and M. C. Gershengorn. 1982. Am. J. Physiol. 242:E109-E114.

18. Martin, T. F. J., and J. A. Kowlachyk. 1984. Endocrinology. 115:1517-1536.

19. Drust, D. S., and T. F. J. Martin. 1984. J. Biol. Chem. 259: 14520-14530.

20. Prentki, M., and C. B. Wollheim. 1984. Experientia (Basel). 40:1052-1060.

21. Valverde, I., and W. J. Malaisse. 1984. Experientia (Basel). 40: 1061-1068.

22. Hutton, J. C., M. Peshavaria, and K. W. Brocklehurst. 1984. Biochem. J. 224:483-490.

23. Howell, S. L. 1984. Diabetologia. 26:319-327.

24. Rink, T. J., and T. J. Hallam. 1984. Trends Biochem. Sci. 9: 215-219.

25. Daniel, J. L., I. R. Molish, M. Rigmaiden, and G. Stewart 1984. J. Biol. Chem. 259:9826-9831.

26. Payne, M. E., C. M. Schworer, and T. R. Soderling. 1983. J. Biol. Chem. 258:2376-2382.

27. Nestler, E. J., and P. Greengard. 1984. Nature (Lond.). 305: 583-588.

28. Nestler, E. J., and P. Greengard. 1983. Science (Wash. DC) 225:1357-1364.

29. Schulman, H. 1984. Trends Pharmacol. Sci. 5:188-192.

30. Berridge, M. J. 1984. Biochem. J. 220:345-360.

31. Michell, R. H. 1975. Biochim. Biophys. Acta. 415:81-147.

32. Machicao, E., and O. H. Wieland. 1984. FEBS (Fed. Eur. Biochem. Soc.) Lett. 175:113-116.

33. Enyedi, A., A. Farago, B. Sarkadi, and G. Gardos. 1984. FEBS (Fed. Eur. Biochem. Soc.) Lett. 176:235-238.

34. Taylor, D., R. J. Uhing, P. F. Blackmore, V. Prpic, and J. H. Exton. 1985. J. Biol. Chem. 260:2011-2014.

35. Charest, R., V. Prpic, J. H. Exton, and P. F. Blackmore. 1985 Biochem. J. 227:79-90.

36. Gomperts, B. D. 1983. Nature (Lond.). 306:64-66. 
37. Haslam, R. J., and M. M. L. Davidson. 1984. FEBS (Fed. Eur. Biochem. Soc.) Lett. 174:90-95.

38. Nakamura, T., and M. Ui. 1983. Biochem. Pharmacol. 32: $3435-3441$.

39. Okajima, F., and M. Ui. 1984. J. Biol. Chem. 259:1386313871.

40. Bokoch, G. M., and A. G. Gilman. 1984. Cell. 39:301-308.

41. Lynch, C. J., R. Charest, P. F. Blackmore, and J. H. Exton. 1985. J. Biol. Chem. 260:1593-1600.

42. Kamata, T., and J. R. Feramisco. 1984. Nature (Lond.). 310: 147-150.

43. Rittenhouse-Simmons, S. 1979. J. Clin. Invest. 63:580-587.

44. Martin, T. F. J. 1983. J. Biol. Chem. 258:14816-14822.

45. Rebecchi, M. J., R. N. Kolesnick, and M. C. Gershengorn. 1983. J. Biol. Chem. 258:227-234.

46. Hughes, B. P., K.-A. Rye, L. B. Pickford, G. J. Barritt, and A. H. Chalmers. 1984. Biochem. J. 222:535-540.

47. Broekman, M. J., J. W. Ward, and A. J. Marcus. 1981. J. Biol. Chem. 256:8271-8274.

48. Kishimoto, A., Y. Takai, T. Mori, U. Kikkawa, and Y. Nishizuka. 1980. J. Biol. Chem. 255:2273-2276.
49. Castagna, M., Y. Takai, K. Kaibuchi, K. Sano. U. Kikkawa, and Y. Nishizuka. 1982. J. Biol. Chem. 257:7847-7851.

50. Naka, M., M. Nishikawa, R. S. Adelstein, and H. Hidaka. 1983. Nature (Lond.). 306:490-492.

51. Roach, P. J., and M. Goldman. 1983. Proc. Natl. Acad. Sci. USA. 80:7170-7172.

52. Jacobs, S., N. E. Sahyoun, A. R. Saltiel, and P. Cuatrecasas. 1983. Proc. Natl. Acad. Sci. USA. 80:6211-6213.

53. Cochet, C., G. N. Gill, J. Meisenhelder, J. A. Cooper, and T. Hunter. 1984. J. Biol. Chem. 259:2553-2558.

54. Shoyab, M., J. E. Delarco, and G. J. Todaro. 1979. Nature (Lond.). 279:387-391.

55. Thomopoulos, P., U. Testa, M.-F. Gourdin, C. Hervy, M. Titeux, and W. Vainchenker. 1982. Eur. J. Biochem. 259:389-393.

56. Lynch, C. J., R. Charest, S. B. Bocckino, J. H. Exton, and P. F. Blackmore. 1985. J. Biol. Chem. 260:2844-2851.

57. DeVirgilio, F., D. P. Lew, and T. Pozzan. 1984. Nature (Lond.). 310:691-693.

58. Zawalich, W., C. Brown, and H. Rasmussen. 1983. Biochem. Biophys. Res. Commun. 117:448-455.

59. Baraban, J. M., R. J. Gould, S. J. Peroutka, and S. H. Snyder. 1985. Proc. Natl. Acad. Sci. USA. 82:604-607. 